\title{
HOMO ABSCONDITUS: O CONTEÚDO UTÓPICO-SUBVERSIVO DAS RELIGIÕES SEGUNDO L. FEUERBACH E E. BLOCH
}

\author{
Rosalvo Schütz ${ }^{1}$
}

\begin{abstract}
Resumo
Com o apoio decisivo da teoria de L. Feuerbach, Ernst Bloch pôde estabelecer, mesmo que de um ponto de vista materialista e até mesmo ateísta, uma relação teórica muito produtiva com a religião. A valorização blochiana da teoria de Feuerbach se situa numa perspectiva não usual na tradição crítica e marxiana a qual, geralmente se limita a indicá-lo como antecessor de Marx, principalmente no que diz respeito à análise do caráter fetichista da sociedade capitalista. Para além dos limites muitas vezes indicados quanto a compreensão histórica, política e antropológica, Bloch reconhece que em Feuerbach há uma verdadeira revolução no modo de compreender e atribuir significado a religião. Muito mais do que superar a religião, segundo Bloch, Feuerbach estava interessado no conteúdo humano e até mesmo subversivo inerente às religiões. Essa apropriação produtiva da teoria de Feuerbach possibilitou a Bloch trabalhar com o pressuposto de que os 'segredos' das religiões se fundam em dimensões humanas latentes, embora ainda não reconhecidas enquanto tal. As religiões estariam, portanto, carregadas de conteúdo utópico, sendo portadoras de um homo absconditus e, simultaneamente, representariam uma fronteira inigualável de emergência do inédito no mundo. O pensamento crítico estaria diante da tarefa de explicitar os conteúdos utópicos e subversivos aí emergentes em vez de abandoná-los ao pensamento e as ações conservadoras.
\end{abstract}

Palavras-chave: Religião. Conteúdos utópicos. Ateísmo antropológico.

\section{HOMO ABSCONDITUS: THE UTOPIC-SUBVERSIVE CONTENT OF RELIGIONS ACCORDING TO L. FEUERBACH AND E. BLOCH}

\begin{abstract}
With the decisive support of L. Feuerbach's theory, Ernst Bloch was able to establish, even if from a materialistic and atheistic point of view, a very productive theoretical relationship with religion. The Blochian valorization of Feuerbach's theory is situated in an unusual perspective within the critical and Marxian tradition which, generally, is limited to indicating him as Marx's predecessor, mainly regarding the analysis of the fetishistic character of the capitalist society. Beyond the limits often recognized in terms of historical, political, and anthropological understanding, Bloch acknowledges that in Feuerbach there is a real revolution in the way of understanding and assign meaning to religion. Much more than surpass religion, according to Bloch, Feuerbach was interested in the human and even subversive content inherent to religions. This productive appropriation of Feuerbach's theory made it possible to Bloch work with the assumption that the 'secrets' of religions are based on latent human dimensions, although not yet recognized as such. Therefore, religions would be filled with utopian content, being holders of a homo absconditus and, simultaneously, representing an unparalleled frontier of the emergence of the untested in the world. Critical thinking would be facing the task of make explicit the utopian and subversive contents emerging therein instead of abandoning them to the thought and conservative actions.
\end{abstract}

Keywords: Religion. Utopian contentes. Anthropological atheism.

1 Docente de Filosofia na Universidade Estadual do Oeste do Paraná - UNIOESTE. Bolsista de produtividade do CNPq. O texto é um dos resultados do pós-doutorado na Universidade Católica do Rio Grande do Sul (PUCRS) entre 2019 e 2020. Uma primeira versão do presente texto foi publicada como capítulo de livro em: Chagas, Eduardo F.; Carvalho, Manoel Jarbas Vasconcelos, Souza, Rayane Marques (Org.). A filosofia Crítica de Ludwig Feuerbach. Homem, natureza e Deus. Porto Alegre: Editora Fi, 2020, p. 222-244. 


\section{1- Contextos:}

"A religião é a consciência primeira, ou seja, indireta do ser humano".

(L. Feuerbach)

Conforme enfatiza Dietschy (2017, p. 185) ${ }^{2}$, Bloch re-localiza de modo subversivo os conteúdos religiosos desde o seu significado "subterrâneo celeste" (himmlisch Unterirdischem), de modo que retrabalha elementos celestes desde uma perspectiva secular: "o que era e aquilo que foi transmitido, ele conta novamente". Trata-se de desvendar o caráter "utópico-subversivo" das religiões a partir da "caixa de tesouros" (Bloch, 1977b, p. 121) nelas contidas. Bloch estava convencido e, ao que parece Feuerbach de algum modo também, de que esses tesouros são capazes de indicar elementos de uma "história subterrânea das revoluções" (1977d, p. 228). É essa "retomada ad hominem de Feuerbach" (1977, p. 280) que interessa à Bloch.

Ernst Bloch compreende a religião como sendo uma das manifestações humanas que, assim como a mitologia e a arte, expressam dimensões humanas que geralmente são “ainda-não-conscientes" (Bloch, 2005, p. 115). Ou seja, aspectos imanentes à realidade que estão emergindo. Manifestações de um mundo em permanente transformação e criação que se originam de uma natureza criadora (natura naturans) e que tem pela frente um horizonte de futuro aberto enquanto ultimum. "Fonte e foz"3, ou seja, ponto de partida e de chegada, se retroalimentam constantemente nesse processo no qual nós humanos, pela nossa práxis histórica, estamos inseridos enquanto co-criadores. Mesmo sendo partícipes da própria criação do mundo que ainda está permanentemente acontecendo e inacabado, quiçá inacabável, Bloch sugere que tenhamos uma postura não prepotente quanto à natureza e à história humana (cf. Schmied-Kowarzik, 2019), afinal, no devir da natureza e da história certamente há muito mais possibilidades de futuro que a nossa momentânea capacidade teórica e prática permitem antever. A possibilidade de um futuro autêntico, com sentido histórico e existencial, só seria possível com base nesse esperançar, que não admite que a história se feche e que percebe que a práxis social e solidária dos seres humanos entre si e com a natureza implica muito mais que racionalização. É preciso estar atento ao que está emergindo!

2 Quando disponíveis edições brasileiras, as referências são feitas em conformidade com as mesmas; quando não, são traduzidas diretamente, mantendo-se a referência da obra original citada.

3 "A nascente é caracterizada pela obscuridade do agora, na qual origina-se o realizar; a foz, pelo caráter aberto do pano de fundo objetal, para onde a esperança ruma” (Bloch, 2006a, p. 284).

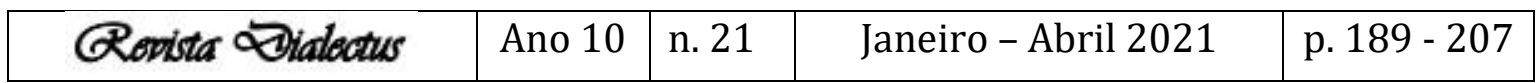


Como parte constitutiva da natureza, a história humana se insere nesse devir. Mas não de um modo determinista, por mais que possa ser condicionada. A postura detetivesca, necessária para perceber os sinais e vestígios (cf. Vidal, 2013) do novo, aparece como sendo um componente imprescindível para a participação ativa dos seres humanos nesse processo. E se de fato, como Bloch pretende demonstrar, todas as manifestações humanas coletivas, por mais alienadas e instrumentalizadas que possam ser, são portadoras de um "excedente cultural" que pode ser colocado a serviço da emancipação e da construção de uma relação não violenta entre humanos e com a natureza, então o desafio está posto permanentemente e em todo lugar. As religiões, nesse contexto, aparecem em Bloch como expressão privilegiada da emergência “de conteúdos jamais manifestados" (Bloch, 2006, p. 281) no mundo, nelas se encontram os “conteúdos utópicos mais potentes" embora e, por isso mesmo, possam ser degradados permanentemente a instrumentos de dominação e opressão. Muitas vezes, inclusive, foi por causa desta instrumentalização conservadora e opressora das religiões, que elas foram confundidas com instrumentos de opressão per se. Bloch, mesmo assim, chama atenção de que é preciso estar alerta frente a "secularização rasa da religião" (Bloch, 2006, p. 372). Busca, por isso, nos conteúdos religiosos, na medida em que deles se apropria e os transforma criticamente, um modo de enriquecer sua análise materialista e, assim, as possibilidades de fortalecimento da utopia concreta. E se de fato "os alvoreceres das profundezas do desejo e de seus tesouros são significativamente distintos das sombras gigantescas da insciência, e quem conseguiu discernir estas ainda não discerniu aqueles" (Bloch, 2006, p. 378) então não se trata apenas de desmascarar a instrumentalização ideológica da religião, mas também de "escavar" e revelar seus tesouros ocultos. Ou seja, Bloch busca na religião também elementos capazes de subsidiar uma práxis social emancipatória ${ }^{4}$ mantendo-se alinhado com a argumentação feuerbachiana, para quem a religião, além de ser uma alienação das características humanas num além, é também o suspiro e protesto da criatura oprimida e, por isso, de certo modo, a esperança de libertação da situação de opressão.

É nesse contexto que Bloch vê na teoria de Feuerbach uma contribuição singular e apropriada. O autor é considerado "um dos ateístas mais importantes e nesse ponto decerto o

Conforme indica M. Löwy (1988, p. 21): "Se poderá discutir longamente entre nós (marxistas e ateus) sobre o enigma filosófico - ou o desafio teórico - que significa o cristianismo marxista do ponto de vista do materialismo histórico ou dialético. Se se define o marxismo antes de tudo como um materialismo (abstrato e metafísico), se trata sem dúvida de uma heresia inaceitável. Se, ao contrário, ele é concebido prioritariamente como uma filosofia da praxis (Gramsci), uma teoria da prática revolucionária de transformação do mundo, sua incorporação por afinidade eletiva no seio do cristianismo revolucionário é perfeitamente compreensível".

\begin{tabular}{|l|l|l|l|l|}
\hline Q ovista Dialectus & Ano 10 & n. 21 & Janeiro - Abril 2021 & p. 189-207 \\
\hline
\end{tabular}


menos compreendido" (Bloch, 2006, p. 376). Uma vez que em Feuerbach não se trata de negar os predicados divinos, mas sim de evidenciar seu caráter profundamente humano a fim de trazêlos justamente para a esfera da imanência. Em sua análise se deixa antever que a religião expressa algo que ainda não se tornou o que poderia ser: base de uma sociedade humana. No entanto, seria preciso libertar-se do caráter ideológico da religião quando essa se equipara a “entronização opressiva contra o ser humano, como aquele estar por cima puro e simples [...] uma quantidade de não-tesouros puramente ideológicos, pertencentes puramente a Igreja dos senhores" (Bloch, 2006, p. 376) a fim de que "os tesouros esbanjados no céu" possam ser recuperados. Daí Bloch afirmar que na teoria de Feuerbach se deixa antever um homo absconditus, que, embora oculto por detrás do véu encobridor das projeções no além, parece estar a espera para ser revelado. Bloch valoriza esses potenciais ao indicar para aspectos utópico-revolucionários presentes nas religiões, um novum a ser desvendando e tornado história pela práxis humana na medida em que esta encontra nele impulsos para a construção do "reino" aqui e agora.

\section{1- Homo absconditus: importância do ateísmo antropológico de Feuerbach}

O reconhecimento da importância da crítica da religião de Feuerbach é muito explícito em Bloch:

Feuerbach fez os conteúdos religiosos retornarem do céu para o ser humano, de tal maneira que o ser humano não foi criado à imagem fiel de Deus, mas Deus à imagem fiel do ser humano, mais exatamente, à imagem do respectivo modelo ideal de ser humano. É verdade que assim Deus desaparece totalmente como criador do mundo, mas obtém-se um enorme âmbito de criação do ser humano, em que - mediante uma ilusão fantástica e simultaneamente uma riqueza fantástica - surge o divino como imagem do desejo humanamente hipostasiada de primeira grandeza. Essa "teoria do desejo da religião" torna-se, para Feuerbach, o mesmo que a "antropologização da religião" ou a revogação da "duplicação celestial do ser humano (Bloch, 2006, p. 368).

A partir dessa leitura Bloch percebe que, de certo modo, a própria concepção de ser humano pressuposta por Feuerbach não é tão anti-histórica e estática como muitas vezes lhes é atribuído $^{5}$. Afinal, a superação da alienação religiosa teria de levar justamente a uma

5 Isso, no entanto, não quer dizer que Bloch não tematize os limites da concepção feuerbachiana em alguns pontos, como, por exemplo, quando sugere que em Feuerbach, "Falta o conjunto sócio-histórico do respectivo typus 'ser humano', faltando sobretudo o seu caráter inacabado" (Bloch, 2006, p. 368). No presente texto, no entanto, procuramos explorar justamente aqueles elementos da teoria de Feuerbach que Bloch destaca e

\begin{tabular}{|l|l|l|l|l|}
\hline Q Rovista Qialectus & Ano 10 & n. 21 & Janeiro - Abril 2021 & p. $189-207$ \\
\hline
\end{tabular}


apropriação humana dos conteúdos inéditos manifestos indiretamente, primeiramente na religião. Segundo Bloch, ainda que se possa constatar, em algumas passagens de sua obra, certo limite na compreensão dos potenciais da religião e de que esses limites provavelmente decorram de sua compreensão de ser humano, possibilitando-lhe perceber apenas um "ser humano tanto genérico quanto estático" (Bloch, 1977, p. 281) oculto nas religiões, de modo que o ser humano, enquanto ser inconcluso, "não é enriquecido por Feuerbach por meio do assalto a sua própria hipóstase no além" (idem), pode-se reconhecer que: "Mesmo assim ninguém tentou reendereçar de modo tão decidido quanto Feuerbach as figuras dos desejos humanos projetados para o além como sendo as que o homem tem de si mesmo" (Bloch, 1977, p. 281). De modo que, tendo em vista a valorização dos predicados e conteúdos da religião no caso específico do cristianismo, pode-se afirmar que ninguém "esteve metodicamente mais radicalmente comprometido como a linha humana do cristianismo" (idem) do que Feuerbach. E na medida em que a própria retomada das características humanas projetadas no além "requer um ato de superação, um ato utópico" (Bloch, 1977, p. 282), no próprio Feuerbach já estão postos elementos para a superação da concepção limitada de ser humano que muitas vezes lhe é atribuída. E se o "[...] segredo das religiões são os segredos dos seres humanos mesmos" então Feuerbach já se encontra no "[...] ante-pátio de um homo absconditus" (idem). O ser humano, portanto, estaria com possibilidade de se tornar algo que nunca antes foi, o humano ainda desconhecido que é definido por Bloch como "o humanum secreto ainda oculto para si mesmo, distinto do humanum conhecido e de seu entorno habitual-imanente" (Bloch, 2006, p. 281). Do que Bloch conclui:

Por essa razão, a antropologização feuerbachiana da religião pressupõe, acaso se queria de fato antropologizar a religião, um conceito utópico do ser humano e não um estaticamente predeterminado. Ela pressupõe igualmente um homo absconditus, da mesma forma que a fé no céu sempre comportou um Deus absconditus, um Deus oculto, um Deus latente (2006, p. 369).

Apoiando-se sobremaneira nesses pressupostos das reflexões da L. Feuerbach, Bloch pôde dar uma passo muito significativo rumo a uma apropriação materialista da religião. Pressuposto, para tanto, é que o "Deus absconditus [...] como tal, não chega a coincidir com o Deus déspota", pois é por meio daquele que "é mantido o problema referente ao que há de

valoriza. O que confere certo ineditismo ao pensamento de Bloch nesse quesito e que abre possibilidades de diálogo e reflexão inovadoras.

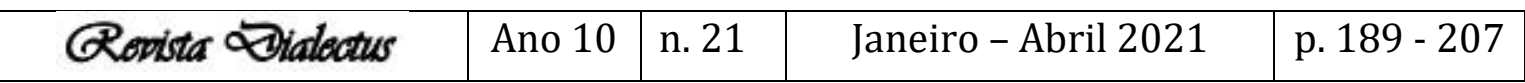


relevante no mistério legítimo do homo absconditus, ao que a comunidade contém de reino na sua esfera definitivamente adequada" (Bloch, 2006, p. 277). Daí, mais uma vez, a importância da contribuição de Feuerbach:

[...] poucos sentiram tão intensamente e situaram tão precisamente o elemento religiosamente não-cumprido durante o século XX quanto Feuerbach, esse ateísta tão significativo. [...] Feuerbach representa uma guinada filosófico-religiosa; [...] Pois ele não pretendia ser apenas o coveiro da religião [...] ele estava antes tomado pelo problema do legado religioso (Bloch, 2006, p. 370).

E é por isso que é importante, tanto do ponto de vista materialista quanto religioso, perceber que Feuerbach só "nega para estatuir" e, ademais, que ele só "desencanta o céu para tornar o ser humano importante" (Bloch, 2006, p. 370). Ou seja, na medida em que Feuerbach não nega os predicados, mas penas o sujeito divino enquanto algo externo e estranho ao ser humano, ele pretende justamente valorizar os predicados humanos. Contribui, assim, para denunciar o caráter ideológico de muitas formas religiosas na medida em que essas são colocadas a serviço de relações de poder, dominação e opressão e, simultaneamente, para anunciar que aquilo que se pré-anuncia (vorscheint) na religião é carregado dos potentes conteúdos utópicos compatíveis com uma utopia concreta/materialista que, no entanto, ainda precisam ser apropriados pela comunidade e práxis humana. Segundo Bloch, Feuerbach estaria constantemente empenhado e motivado por essas duas perspectivas em sua crítica, quais sejam “[...] o desejo de alcançar nossa essência e ao mesmo tempo a fantástica alienação de nossa essência, mediante sua penhora no céu" (Bloch, 2006, p. 370). Denúncia e anúncio de certa forma se condicionariam mutuamente em sua obra. E, na medida em que o que há de mais humano é projetado no céu, a fé em tudo que é atribuído ao além é, por isso, a fé, mesmo que indireta, no ser humano. É o que Bloch expressa ao citar Feuerbach: „A fé no além é a fé na liberdade da subjetividade em relação às restrições da natureza - logo, a fé do ser humano em si mesmo" (Feuerbach apud Bloch, 2006, p. 372). Na religião se revela algo que

[...] jamais ocorreu em parte alguma, em suma, uma perfeição que corresponderia utopicamente à necessidade da esperança. No ápice do idealizado encontrava-se desde os tempos antigos, o divino, seja porque aos deuses é permitido e são capazes de fazer o que ao ser humano não é permitido e que ele não pode, seja porque eles são os que não se encontram situados, os de conduta bem-aventurada em si (Bloch, 2006, p. 367).

Por mais que a religiões, assim como a ciência, a arte e a mitologia, tenham sido instrumentalizadas para a legitimação de relações de poder, dominação e opressão, seu

\begin{tabular}{|c|c|c|c|c|}
\hline Q Rovista Dialectus & Ano 10 & n. 21 & Janeiro - Abril 2021 & p. $189-207$ \\
\hline
\end{tabular}


conteúdo utópico e subversivo não consegue ser aniquilado/anulado totalmente. Ainda permanece o "suspiro da criatura oprimida", o desejo subversivo de transcender, pois "[...] todas as explicações e dissoluções psicogênicas de uma ilusão transcendente não conseguem diluir totalmente aquilo que deu origem à transfiguração em céu” (Bloch, 2006, p. 371). São estes conteúdos que transcendem a "ilusão transcendente", enquanto "tesouros da esperança" (cf. Schütz, 2020) os quais Bloch busca valorizar. Para tanto defende uma concepção própria, de origem feuerbachiana, de ateísmo:

Porém, nenhum ateísmo que liberta do temor libertaria dos conteúdos do desejo e dos tesouros da esperança da religião, exceto na sua forma mais mirrada e totalmente negativa, no materialismo vulgar do século XIX, que só se manteve afastado da perda completa desses conteúdos da esperança, portanto, do niilismo, graças ao seu filistério culto. $\mathrm{O}$ ateísmo trouxe esses tesouros transcendentes novamente para a imanência; em Feuerbach, ele os trouxe de modo bem ponderado para dentro do ser humano (Bloch, 2006, p. 376).

A crítica feuerbachiana da religião jamais deixa de ser crítica, pois ela não subsiste sem denúncia de algo. Porém, essa crítica não é niilista. Ela simultaneamente anuncia algo enquanto possibilidade real: utopia concreta. Em vez de "candidatos ao além" Feuerbach quis tornar possíveis "estudantes do aquém" que, estando em busca de um "reino da liberdade" se ocupem com a construção de um "aquém melhor" (Bloch, 1977, p. 282). O ateísmo antropológico (cf. Souza, 1994) pretende justamente recuperar aquilo que há de humanamente oculto por de trás de tão poderosa manifestação. No entanto, é preciso levar em conta que, se, por um lado, os conteúdos religiosos não são "totalmente quiméricos para o ateísmo antropológico" por outro lado, também é preciso cuidar para “que não sejam o que são na ilusão da teologia - mistérios estrangeiros - mas que sejam mistérios autóctones, os mistérios da natureza humana'” (Bloch, 2006, p. 370). A crítica, por isso, não deveria nem aceitar a religião como simples justificação ideológica tampouco submetê-la a uma crítica grosseira, até porque “[...] a trivialidade do pseudoiluminista sempre é rompida por força do humano que não é mais fraco nem menos misterioso do que a natureza. [...] Esse pano de fundo que não deve ser esquecido da imanência humanista no sentido radicalmente legatório" (Bloch, 2006, p. 372). $\mathrm{Ou}$, como afirma Bloch em outra passagem, é preciso ter cuidado para "que a criança não seja derramada junto com a água do banho" (Bloch, 1977, p. 20): a denúncia da instrumentalização ideológica não deveria cegar para os autênticos conteúdos subversivos das religiões.

Com tal postura iniciada por Feuerbach, Bloch $(1977 b, 121)$ consegue visualizar uma possibilidade de rastrear conteúdos "utópico-subversivos" contidos no "ideal utopicamente

\begin{tabular}{|l|l|l|l|l|}
\hline Qovista Dialectus & Ano 10 & n. 21 & Janeiro - Abril 2021 & p. 189-207 \\
\hline
\end{tabular}


hipostasiado do ser humano desconhecido" (2006, p. 367) de todas as religiões, por mais instrumentalizadas, degradadas e ideologicamente vilipendiadas que elas tenham sido. Em vez de ser considerada enquanto um estágio de desenvolvimento humano a ser superado, Bloch passa a ver nas religiões possíveis aliadas. Para tanto, porém, seria preciso uma postura teórica específica:

[...] todas as designações e nomeações de Deus se constituíram em gigantescas figurações e tentativas de interpretação do mistério humano: perpassando ideologias religiosas e, apesar dessas ideologias, visando a figura humana oculta. [...] O simultaneamente familiar e totalmente-outro, como signo do estrato religioso, desde os deuses animais até o único Deus onipotente, até o Deus salvador, só se torna compreensível como essa projeção interpretativa do homo absconditus e seu mundo (2006, p. 372).

Além disso, Bloch busca explicitamente ampliar a concepção feurbachiana para além da esfera puramente humana em direção a toda natureza, já que “[...] não é somente o sujeito que deve ser concebido de modo utópico, [...] mas também a natureza que o circunda; ela de modo algum deve apresentar-se como finalizada como a natureza materialista-mecânica" (2006, p. 360). O próprio Feuerbach, segundo Bloch, teria percebido isso em obras posteriores [como na Teogonia (1969)] e buscado ampliar sua concepção nessa direção. Seja como for, vemos aqui a concepção de natureza enquanto autoprodutiva voltando a ser referência também para pensar os processos emancipatórias desde uma perspectiva utópico-subversiva. Importa reconhecer que com Feuerbach se tornou possível perceber algo inédito no campo materialista: “A esperança que laborou na religião e agora ficou desprovida de ilusão, de hipóstase, que se tornou não mitológica, intenciona, pois, mediante a idéia do reino, fazer arder uma luz utópica tanto na possibilidade subjetal quanto na margem da possibilidade objetal" (Bloch, 2006, p. 369). E Bloch dedica muita investigação e elaboração para demonstrar esta possibilidade. Vejamos:

\section{3- "A crítica reconduz os conteúdos religiosos ao desejo humano".}

Mas como, mesmo sabendo desse potencial humano contido nas religiões, impedir que estas sejam degradadas a simples instrumentos ideológicos e justificação de relações sociais de opressão e dominação? Bloch não parece ver outra perspectiva a não ser sua permanente reelaboração crítica desde um ponto de vista materialista, crítica esta possível especialmente desde a "corrente fria do marxismo". A "crítica reconduz os conteúdos religiosos ao desejo 
humano" de modo que Deus enquanto expressão do desejo maior e mais radical surge "como ideal hipostasiado da essência humana que ainda não ganhou existência real; ele surge como enteléquia utópica da alma, assim como o paraíso era imaginado como enteléquia utópica do mundo divino" (Bloch, 2006, p. 373). No entanto, até mesmo do ponto de vista da análise decorrente da "corrente fria", é preciso ter cuidado para não para não agir de forma rasa e grosseira, tendo em vista que nas religiões podem manifestar-se conteúdos utópicos inéditos à todo momento e que "[...] em crescente profundidade são tanto religiões do antropos desconhecido quando do antropos que começa a sair do seu anonimato" (Bloch, 2006, p. 373). Esse excedente cultural das religiões, que ultrapassa sua eventual instrumentalidade histórica/conjuntural, Bloch denomina de metareligião:

[...] o ateísta que compreendeu o que se imaginava sob Deus como uma indicação para o conteúdo humano ainda não manifestado não é nenhum anticristo. [...] Por essa razão, esse elemento utópico é e continuará sendo irreligioso, ao ser contundentemente metareligioso, o que quer dizer que ele faz parte do ateísmo advindo e finalmente compreendido em suas dimensões profundas; porém, o conceito de ateísmo, de acordo com o seu positivum último, é o reino da liberdade (Bloch, 2006, p. 377).

O mesmo "reino dos céus" da tradição judaico-cristã, o qual por vezes já na bíblia é transcrito subvertidamente enquanto "reino dos homens", ou seja, da imanência terrestre, enquanto um ultimum messiânico a ser alcançado, é equiparado com a noção marxiana de reino da liberdade, evidenciando uma perspectiva semelhante, agora, no entanto, liberto da sua projeção no além, sendo antes uma motivação para o engajamento e a práxis: sentido orientador de construções históricas/humanas. Nesse contexto Bloch chega a afirmação de que, levada às últimas consequências "a intenção religiosa do reino como tal implica ateísmo" (2006, p. 282). Assim, por exemplo, o cristianismo primitivo, baseado na vivência comunitária e na resistência e luta contra o império romano, era antes contraste do que esquema de justificação:

\footnotetext{
A pregação de Jesus [...] por ser escatológica, era a que menos selava a paz com o "presente éon" [...]. Pra ela, era bem mais fundamental do que para outras religiões ser contraste, tendo se iniciado de fato como movimento social entre os fatigados e sobrecarregados; ela trouxe a estes fatigados e sobrecarregados ao mesmo tempo um impulso, uma auto-estima e uma esperança, que a mera opressão jamais teria podido encontrar, ao menos durante quatro mil anos, não desta forma (Bloch, 2006, p. 275).
}

Evidentemente esse impulso de caráter subversivo, enquanto movimento social dos "fatigados e sobrecarregados" foi profundamente transfigurado num processo de degradação, a

\begin{tabular}{|l|l|l|l|l|}
\hline Qevista Dialectus & Ano 10 & n. 21 & Janeiro - Abril 2021 & p. 189-207 \\
\hline
\end{tabular}


ponto de muitas vezes não parecer passar de uma simples ideologia de justificação do status quo. Mesmo assim, na visão de Bloch, esse impulso original nunca pôde ser totalmente eliminado, tendo sempre existido correntes subterrâneas heréticas que retomavam aquele impulso subversivo e humano original:

\begin{abstract}
E se é válida a sentença “onde há esperança, há religião", então o cristianismo, com seu ponto de partida vigoroso e sua rica história de heresias, [...] não o mito estático, consequentemente apologético, mas o messianismo escatológico-humano, consequentemente de constituição explosiva. [...] O vigor exatamente dessa perfeição explosiva foi crescente e rica e, assim, também é inegável a profundidade da formação projetiva de deuses do desejo, que corresponde à intensidade do engajamento humano (2006, p. 276).
\end{abstract}

Por mais conservadores que os conteúdos religiosos pareçam à primeira vista e muitas vezes de fato sejam, quando submetidos à uma hermenêutica subversiva (cf. Raulet, 2017, p. 338) que também poderia ser denominada de hermenêutica da esperança, libertandoos do seus invólucros teocráticos e ideológicos, eles revelam conteúdos utópico revolucionários. Por isso Bloch afirma mais tarde, de forma inversa, que "Onde há religião, também há esperança” (1977, p. 23) , ou seja, mesmo que nem toda esperança implique necessariamente algo religioso, a religião não pode existir sem alguma forma de esperança na possibilidade de um ser humano e um mundo melhor. É preciso considerar, segundo Bloch, que as instituições de poder não são a fonte da religião, pelo contrário, elas penas se apropriaram das mesmas e buscam instrumentalizá-las o quanto podem. As religiões tem outra origem: “As fontes para tanto vertem de outro lugar" (Bloch, 1977, p. 88) que não as instituições mesmas. O cristianismo, por exemplo, não deveria, segundo Bloch, ser reduzido a um "Deus das igrejas" que está a serviço "da sociedade de classes" (idem), por mais que, nas instituições que se intitulam suas fiéis depositárias, muita vezes, tenham assumido esse papel. Por isso, Bloch busca demonstrar que o "Deus de Moisés" transmite uma consciência utópica, sendo antes um Deus que exorta para a busca do 'novo céu e da nova terra', que "promete a saída da escravidão do Egito e, através do deserto, levar para a terra da liberdade” (1977, p. 109). Moisés, enquanto expressão humana de Deus seria, por isso, considerado o Deus do êxodo, ou seja, que assegura sua "hostilidade contra o ópio e os seus senhores" (Idem). Segundo Bloch (2006, p. 319-320), essa força revolucionária do Deus de Moisés, só foi neutralizada "quando a classe dominante passou a se apropriar desta imagem deturpando-a a tal ponto que o [...] Deus creator, de um mundo apresentado como muito bom e já pronto, e o Deus spes, que Moisés proclama ao seu 
povo, passam a ser idênticos", 6 e isto tanto na teologia rabínica quanto, mais tardiamente, também na igreja cristã. Por isto, segundo Bloch, no caso específico da relação com o cristianismo, "o autêntico marxismo leva à sério o autêntico cristianismo" e isso especialmente em torno do objetivo comum da libertação dos pobres e oprimidos, como referência de um “conteúdo substancial da consciência revolucionária” (1977, p. 354). Haveria, pois, uma finidade eletiva (cf. Löwy, 2005, p. 58) substancial entre religião/cristianismo e marxismo.

\title{
4- $\quad$ Entre o céu e o inferno: a importância messiânica da práxis
}

\author{
O que nenhum olho viu e nenhum ouvido ouviu \\ e não entrou em nenhum coração humano é o que \\ Deus preparou para os que o amam \\ (I Cor 2: 9 lapud Bloch, 2006, p. 373).
}

Segundo Bloch, de modo geral, os ateísmos concordam que nas religiões se desenvolvem arquétipos e tesouros humanos da mais alta significância emancipatória. Tesouros estes que em Feuerbach foram trazidos de modo refletido para dentro dos seres humanos. De modo que, uma compreensão atualizada de ateísmo já não despreza esses tesouros: "Entrementes, porém, as perguntas por Deus tornaram-se suficientemente inteligentes para conferir um caráter positivo ao ateísmo justamente como entrada em cena daquilo que foi desvalorizado ou transferido pela fé em Deus" (Bloch, 2006, p. 375). Isso, no entanto, não quer dizer, que a função da "corrente fria" do marxismo deva ser paralisada. Pelo contrário, a hermenêutica subversiva, além de indicar os tesouros e segredos humanos revelados pela religião, jamais pode ficar sem denunciar suas instrumentalizações ideológicas ou mesmo idolatrias: “A verdade do ideal de Deus é constituída unicamente pela utopia do reino, e o pressuposto para esta é exatamente que não permaneça nenhum Deus nas alturas, já que de qualquer modo não há nenhum lá nem nunca houve" (Bloch, 2006, p. 374), ou, dito de outro modo: "A existência de Deus, sim, Deus de um modo geral como um ente é superstição; fé é unicamente a voltada para o reino de Deus messiânico - sem Deus” (Bloch, 2006, p.283). Não se trata, portanto, de justificar e desenvolver as religiões em suas versões institucionalizadas:

O que se salva, o que pode ser herdado após uma reformatio in capite et membris [reforma completa] é, portanto, unicamente o conteúdo do desejo e a profundidade da

6 Conforme o teólogo Moltmann: "O ateísmo apaixonado de Bloch contra qualquer religião de senhores serve para libertar a fraternidade dos crentes e pobres assim como a verdadeira esperança cristã dos ídolos, das falsas alianças e dos abusos" (Apud Hartmann, 2012, p. 49).

\begin{tabular}{|c|c|c|c|c|}
\hline Q Rovista Dialectus & Ano 10 & n. 21 & Janeiro - Abril 2021 & p. $189-207$ \\
\hline
\end{tabular}


esperança que se manifestaram nas imagens religiosas, transcendendo a insciência e a pura fantastiquice (Bloch, 2006, p.378).

Aquilo que pré-apareceu, laborou na religião, passa, de modo transformado, a ser base de uma utopia concreta, é a ideia de um "reino dos céus" que passa a significar reino sobre a terra, reino da liberdade. Conforme Bloch (2006, p. 396) as religiões, de modo geral, sempre buscam "[...] uma terra em que o leite e o mel manam tanto real quanto simbolicamente; o alvo do ateísmo [...] é exatamente o mesmo - sem Deus, mas com a face descoberta do nosso absconditum e da latência da salvação na terra árida". Ou seja, a esperança que ainda labora no obscuro da religião precisa e pode se tornar "[...] luz utópica tanto na possibilidade subjetal quanto na margem da possibilidade objetal" (Bloch, 2006, p. 369) em meio à práxis social.

Essa tendência para o "novo possível" (Bloch, 2005, p. 17) inerente a todo ser humano (cf. Schütz, 2017) e manifesto especialmente na religião, permanece sempre instigando a esperança "mesmo que a esperança não mais tenha por objeto real um Pater noster, qui es in coelis [Pai nosso que estais no céu], um objeto separado apenas em termos de espaço num supra-espaço supostamente existente" (Bloch, 2006, p. 368). E assim se abre a possibilidade de que "marxismo e religião possam se unificar na vontade pelo reino" (Bloch, 1977c, p. 346), ou seja, desde um ser humano e mundo "ainda em criação" e rumo a um reino onde possamos nos sentir em casa (Heimat) em meio ao outros seres humanos e com a natureza. E, evidentemente que, para tanto pressupõe-se uma concepção ampliada tanto de matéria quanto de religião (cf. Löwy, 2005) de modo que uma afinidade eletiva entre ambas possa ser produtivamente explicitada.

Em não se admitindo mais "um objeto separado [...] num supra-espaço", segundo Bloch, se abre, inclusive, mais um campo de reflexão e atuação para o pensamento crítico. Pois esse espaço vazio, que passou a existir depois da não mais admissão de um ser externo para preenchê-lo, não é uma quimera que desaparece com o esvanecer da ilusão transcendente. Ou seja, naquele espaço que resta depois que a hipótese Deus foi superada ainda permanece um espaço vazio e, tendo em vista que aí "também não se trata de nenhuma quimera“" (Bloch, 2006, 378) sendo antes uma garantia para "manter-se aberto para uma realidade futuramente possível, ainda não determinada, nesse espaço vazio [...]" (Bloch, 2006, p. 379), sendo por isso mais um dos poderosos legados religiosos a ser levado em conta pelo materialismo.

Nas palavras de Bloch: 
[...] o que dizer do espaço vazio que a liquidação de hipótese "Deus" deixa ou não deixa como sequela? [...] Ou o problema do lugar para dentro do qual os deuses foram imaginados seria apenas um problema aparente que se resolve por si mesmo com o fim da aparência religiosa? [...] Ou então: o vazio para dentro do qual foram projetadas as ilusões divinas não existiria ao menos como tal vazio? (2006, p. 378).

Bloch recorre a uma analogia com o problema enfrentado por Leibniz quando este encontra uma solução para a polêmica entre racionalistas e empiristas, no que diz respeito a polêmica sobre origem do conhecimento, onde uns defendiam que tudo se originava dos sentidos e outros da razão. Polêmica essa e resolvida por Leibniz com a afirmação de que tudo que se encontra no entendimento advém dos sentidos, com exceção do próprio entendimento. Analogamente Bloch questiona em relação à religião: "Se o conteúdo cai por terra, o recipiente necessariamente cai junto?” (2006, p. 378). Segundo Bloch, poder-se afirmar que tudo que está projetado para dentro daquele "espaço" onde se localizava Deus pode ser questionável, porém não este espaço, esta capacidade humana mesma. Por isso, para ele, “[...] o problema do espaço de projeção religiosa por si só não representa um problema aparente, e, embora esse espaço de modo algum seja uma realidade no sentido do existir fático, também não se trata de nenhuma quimera" (2006, p. 339). Indica antes uma possibilidade permanentemente aberta e constitutiva do ser humano:

[...] o espaço vazio religioso não é nem será uma quimera, embora todos os deuses que estavam nele o fossem. O homo absconditus conserva, portanto, uma esfera permanente preordenada em que ele, caso não venha a perecer, pode intencionar a sua manifestação mais fundamental no mundo que lhe foi franqueado (Bloch, 2006, p. $382)$.

Para Bloch este espaço vazio é um "tópos aberto do diante-de-nós, o novum" onde pode existir tanto o "nada autêntico" quanto o "tudo ou a sua consumação pelo regnum humanum ou reino [...] Na medida em que o espaço vazio pode conter tanto o nada quanto o tudo, ele se chamava inferno ou céu" (2006, p. 380-381). E o que decide entre o tudo e o nada, movendo-se nesse campo de possibilidades que é o mundo e a história, é a práxis humana, pois aí que se encontra "[...] a fermentação, esfera aberta de atuação à disposição do sujeito humano" (Bloch, 2006, p. 380), um "[...] espaço da identificação possível de tudo o que se move e que está nascendo tanto no ser humano quanto no mundo" (Bloch, 2006, p. 382) e é o que nos torna seres para quem sempre "falta algo" (cf. Lorenzoni, 2019) instigando-nos permanentemente para frente, para aquilo que pode ser.

Importante é

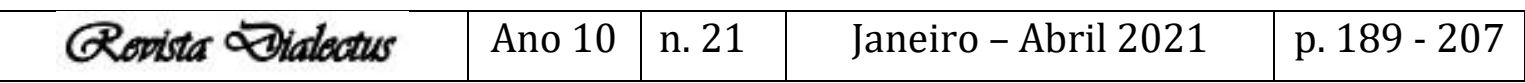


[...] manter-se aberto para uma realidade futuramente possível, ainda não determinada, nesse espaço vazio; [...] Nada seria mais errôneo, na medida em que se leva o ateísmo a sério em termos objetais e não apenas antropológicos, nada seria mais errôneo do que tirar disso a consequência leviana de uma fé num espaço vazio em que não se encontraria nenhum tipo de existência, nem mesmo o correlato de um ser utópico em lugar do de Deus, de um ainda-não-ser como o do ... reino (Bloch, 2006, p. 379).

É esse espaço vazio que garante a continuidade da história humana e fundamenta a importância messiânica da práxis, pois é nela que, à rigor, se decide pelo céu ou pelo inferno: "Nada e tudo, caos e reino, estão nos pratos da balança da área de projeção outrora religiosa; é o trabalho humano na história que exerce uma influência de peso no prato do nada ou então na do tudo” (Bloch, 2006, p. 380). Por isso Bloch pôde concluir que: „Se sem ateísmo não há utopia do reino, então tampouco há utopia sem o espaço vazio real-utópico que o ateísmo tanto deixou restar quanto abriu. [...] o reino, no entanto, precisa de lugar” (2006, p. 382). Ou seja, há uma dimensão constitutiva do ser humano que o impele permanentemente para transcender o existente, a não se acomodar por completo pelo que já é, pois há sempre um "espaço vazio" no ser onde nós humanos, através da práxis histórica, podemos laborar. Este espaço indica, inclusive, para a possibilidade de uma natureza abscôndita, ou seja, ela mesma ainda está se produzindo, nunca está totalmente completa e nós humanos, como constituintes dela, somos uma de suas expressões mais explícitas. Segundo Bloch, se é possível perceber um "conteúdo humano ainda não manifestado associado ao conteúdo utópico da natureza" (2006, p. 376) então é possível recuperá-lo tanto para o "sujeito humano, [quanto] para o possível sujeito da natureza, para o alvorecer do incógnito em ambos" (2006, p. 378). E essas, como afirma Dietschy (2019, p. 164) parecem ser "as condições transcendentais para uma práxis social acertada”, pois sem essas possibilidades antropológicas e naturais para transcender o existente sem precisar recorrer a um ente transcendente, a práxis social certamente permaneceria bloqueada.

Por fim, cabe retomar que em decorrência dessa análise dos potenciais da religião, de certo modo, Bloch, apoiando-se ainda em Feuerbach, retoma até mesmo a concepção de natureza subjacente a sua própria reflexão. $\mathrm{O}$ faz, especialmente no momento em que indica que Feuerbach, em obras posteriores como na Teogonia (1969), reconheceu explicitamente a existência desse espaço vazio no ser humano mas também na própria natureza. Uma abertura constante para o inédito que Feuerbach teria reconhecido, mesmo sem abdicar de seu ateísmo, mas reconsiderando sua "antropologia demasiado pura", recorrendo, por isso, à natureza:

\begin{tabular}{|l|l|l|l|l|}
\hline Q ovista Dialectus & Ano 10 & n. 21 & Janeiro - Abril 2021 & p. $189-207$ \\
\hline
\end{tabular}


Ele não teve outro jeito do que encontrar algo, se não no além extinto, então na natureza igualmente destituída de deuses, ainda encontrar algo que faça com que a projeção não fique tão suspensa no ar. Já que, para ele, a natureza é co-participante da projeção religiosa, associam-se às meras imagens do desejo até mesmo objetos, a saber, os da sensualidade exterior. Desse modo, para o Feuerbach tardio, os deuses, na 'teogonia' ${ }^{7}$ ( $\mathrm{sic}$ ), não são apenas seres do desejo, mas ao mesmo tempo também seres da natureza (Bloch, 2006, p. 380).

Mas deixemos as reflexões sobre a possibilidade de um "sujeito natureza" [natura naturanz] (Bloch, 1977a) e que certamente nas religiões naturais também indica conter "conteúdos subversivos" suficientemente potentes para indicar pistas para a libertação de nossas visões de mundo demasiadamente antropocêntricas, e para a construção de uma "técnica da aliança" que supere a técnica da violação: natura absconditus!

\section{5- Considerações finais}

Do exposto pode-se afirmar que a crítica da religião de Feuerbach foi decisiva para a relação crítico/produtiva de $E$. Bloch no que diz respeito a uma apropriação crítico/materialista da religião. Algo inédito do campo materialista, uma vez que, apesar das reservas críticas, reconhece a religião enquanto espaço de encubação e desenvolvimento de utopias com conteúdos humanos únicos. Depois de Bloch, além da crítica permanente ao caráter teocrático/ideológico, o pensamento crítico está diante do desafio de desvendar o homo absconditus latente em todas as manifestações religiosas. Feuerbach, ao intentar, por meio de seu ateísmo antropológico, devolver aos seres humanos algo que havia sido projetado no além, pressupõe, [mesmo que não o tenha dito desta forma] uma espécie de utopia histórica, pois indica que há potenciais humanos latentes na religião que podem se tornar realidade. O ateísmo de Bloch, nas trilhas de Feuerbach, não é um ateísmo niilista: além de contribuir para que as religiões não se degradem a "ideologias dos senhores", quer se aproximar dos "tesouros humanos" ocultos nas religiões e, assim, enriquecer o horizonte materialista e suas possibilidades de práxis.

Bloch, no entanto, mesmo apoiando-se em Feuerbach, dá alguns passos para além deste. Assim, por exemplo, enfatiza explicitamente que a religião pode revelar características

\footnotetext{
7 Trata-se aqui do escrito de Feuerbach intitulado Teogonie (1964).
}

\begin{tabular}{|l|l|l|l|l|}
\hline Qonista Dialectus & Ano 10 & n. 21 & Janeiro - Abril 2021 & p. 189-207 \\
\hline
\end{tabular}


humanas totalmente inéditas, ainda desconhecidas dos seres humanos. Não se trata, pois, apenas de recuperar algo que já tenha existido e tenha sido perdido (cf. Dietschy, 2018), mas da possibilidade de um futuro autêntico, ou seja, de algo que nunca antes foi dessa forma e da realização desse potencial por meio da práxis humana. Mesmo assim, essas possibilidades não são mera utopia abstrata, pois se revelam objetivamente possíveis naqueles conteúdos de esperança inerentes às religiões: são a base para uma utopia concreta. Por meio de uma hermenêutica da esperança, constitutiva de uma filosofia que se caracterizaria fundamentalmente pelo seu aspecto detetivesco, é possível extrair conteúdos culturais excedentes/subversivos de todas as religiões, uma vez que não há possibilidade de religião sem esperança.

Se tanto a matéria, enquanto fonte primeira de todos os processo, encontra-se em constante modificação e criação, quanto a foz, o horizonte de futuro, mantém se constantemente abertos, então a práxis social, que se situa em meio a esse campo tenso, encontra nos conteúdos de esperança revelados pelas religiões aportes sem igual, especialmente na constituição de um horizonte de esperança, sem o qual toda práxis perde o sentido. Horizonte este indicado tanto pelo "reino de Deus" aqui e agora quanto pelo "reino da liberdade" sugerido por Marx. É nesse contexto que as condições de possibilidade da práxis e de seu caráter messianicamente decisivo "entre o céu e o inferno" se revelam. É o anúncio que se revela por meio da denúncia e viceversa.

Bloch, ao não reduzir a religião a uma ilusão, valoriza até mesmo "aquele recipiente" humano geralmente ocupado pelas projeções religiosas. $\mathrm{O}$ valoriza enquanto espaço aberto para o novo, para a esperança e sem a qual o ser humano não poderia contar com um futuro autêntico. É uma espécie de imunização contra degradações ideológica e determinismos das mais diversas formas. Ao se apoiar em Feuerbach segundo o qual esta dimensão seria originária da própria natureza, Bloch parece indicar para a possibilidade e que, além de um homo absconditus, as religiões revelariam também uma natura abscôndita. O que é coerente com sua concepção de matéria (fonte) e com o horizonte (foz) a ser buscado, onde a humanização da natureza seja simultaneamente a naturalização do ser humano e vice-versa (cf. Schmied-Kowarzik, 2019a).

Por fim, Bloch parece extrair uma função messiânica da religião, que, no entanto, só adquire sentido secular quando inserida no contexto da práxis social. O "caráter explosivo" da religião, só pode se tornar prática libertária, após ser criticamente apropriado por uma 
hermenêutica subversiva e inserido em um horizonte de uma práxis social renovada. Não se trata de atualizar e efetivar essências já prontas, mas de identificar, dar voz, des-teocratizar e valorizar aquilo que nunca foi dessa forma, mas que pode ser.

\section{Referências Bibliográficas:}

BLOCH, Ernst. Atheismus im Christentum. Zur Religion des Exodus und des Reichs. Gesamtausgabe 14. Frankfurt a. M.: Suhrkamp,1977.

BLOCH, Ernst. Experimentum mundi. Fragen, Kategorien des Herausbringens, Praxis. Frankfurt a. M.: Suhrkamp, 1975/1977a.

BLOCH, Ernst. Erbschaft dieser Zeit. Frankfurt a. M.: Suhrkamp,1977b.

BLOCH, Ernst. Geist der Utopie. Zweite Fassung. Frankfurt a. M.: Suhrkamp, 1977c.

BLOCH, Ernst. O princípio esperança, Vol. I. Tradução de Nélio Schneider. Rio de Janeiro: EdUERJ: Contraponto, 2005.

BLOCH, Ernst. O Princípio Esperança Vol. II. Tradução de Werner Fuchs. Rio de Janeiro: EdUERJ: Contraponto, 2006a.

BLOCH, Ernst. O princípio esperança, Vol. III. Tradução de Nélio Schneider. Rio de Janeiro: EdUERJ: Contraponto, 2006

BLOCH, Ernst. Thomas Münzer als Theologe der Revolution. Frankfurt a. M.: Suhrkamp, 1921/1977d.

CHAGAS, Eduardo Ferreira. Natureza e Liberdade em Feuerbach e Marx. Campinas, SP: Editora Phi, 2016.

CHAGAS, Eduardo Ferreira. A primazia da natureza ante o espírito em Ludwig

Feuerbach. In: Trans/Form/Ação. Vol. 32 no. 02, Marília, 2009.

DIETSCHY, Beat. Karl Marx und die Apokalypse. Eine Mesalliance? In: ZEILINGER, Doris (Org.). VorSchein 36. Jahrbuch 2018 der Ernst-Bloch-Assoziation. Marxismus und Philosophie. Antogo Verlag: Nürnberg, 2019, p. 153-164.

DIETSCHY, Beat. Auf der Spur von ,himmlisch Unterirdischem“. Acht Thesen zu Ernst Bloch Transformation der Religion. In: ZEILINGER, Doris (Org.). VorSchein 35. Jahrbuch 2017 der Ernst-Bloch-Assoziation. Der Zukunft auf der Spur. Antogo Verlag: Nürnberg, 2018, p. 185-197.

FEUERBACH, Ludwig. Essência do cristianismo. Campinas, SP: Papirus, 1988.

\begin{tabular}{|c|l|l|l|l|}
\hline Genista & Ano 10 & n. 21 & Janeiro - Abril 2021 & p. $189-207$ \\
\hline
\end{tabular}


FEUERBACH, Ludwig. Princípios da Filosofia do Futuro. LusoSofia: press. Covilhã, 2008.

FEUERBACH, Ludwig. Teses provisórias para a reforma da filosofia. LusoSofia: press. Covilhã, 2008.

FEUERBACH, Ludwig. Preleções sobre a essência da Religião. Campinas, SP: Papirus, 1989.

FEUERBACH, Ludwig. Theogonie nach dem Quellen des klassischen, hebräischen und christlichen Altertums, GW 7. Org. por W. Schuffenhauer. Berlim: Akademie, 1969.

HARTMANN, Heiko. Atheismus. In: DIETSCHY, Beat; ZEILINGER, Doris; ZIMMERMANN, Rainer (Hrg.). Bloch-Wörterbuch. Leitbegriffe der Philosophie Ernst Blochs. Berlin: Walter de Gruyter, 2012, p. 38-51.

LORENZONI, Anna Maria. "Não esqueça o melhor": tema e variações da sinfonia ética em O Princípio Esperança de Ernst Bloch. Tese de doutorado. Toledo: Programa de PósGraduação em Filosofia da UNIOESTE, 2019.

LÖWY, Michael. Marxismo e religião: ópio do povo? In: BORON, Atilio A.; Amadeo, Javier; Gonzalez, Sabrina. A teoria marxista hoje. Problemas e perspectivas. CIDADE: EDITORA, 2007.

LÖWY, Michael. Mística revolucionária: José Carlos Mariátegui y la religion. In: Utopia e práxis latino-americana. Revista Internacional de Filosofía Iberoamericana y Teoria Social. Faculdade de Ciência Econômicas e Sociales, Universiade del Zulia, n. 28. Maracaibo/Venezuela, 2005.

LÖWY, Michael. Ópio do povo? Marxismo crítico e religião. In: Revista Movimento: Crítica, teoria e ação. Abril 2018. Disponível em: https://movimentorevista.com.br/2018/04/opio-dopovo-marxismo-critico-e-religiao-michael-lowyl. Acesso em: 09 out. 2019.

RAULET, Gérard. Die Utopie des Reichs. In: ZIMMERMANN, Rainer (Org.). Ernst Bloch: das Prinzip Hoffnung. Reihe Klassiker Auslegen. Herausgegeben von Otfried Höffe. De Gruyte, 2017, p. 337-357.

SCHMIED-KOWARZIK, Wolfdietrich. Ernst Bloch: esperança por uma aliança entre história e natureza. Tradução de Rosalvo Schütz. In: Revista Veritas. Porto Alegre, v. 64 (3) e34619, 2019. https://doi.org/10.15448/1984-6746.2019.3.34619

SCHMIED-KOWARZIK, Wolfdietrich. A relação dialética do homem com a natureza. Estudos histórico-filosóficos sobre o problema da natureza em Karl Marx. Tradução de Rosalvo Schütz. Cascavel: Edunioeste, 2019a.

SCHÜTZ, Rosalvo. Immanez und Latenz der kleinen Tagträume. In: ZIMMERMANN, Rainer (Hrg). Ernst Bloch: das Prinzip Hoffnung. Reihe Klassiker Auslegen. Herausgegeben von Otfried Höffe. De Gruyte, 2017, p. 35-49.

\begin{tabular}{|l|l|l|l|l|}
\hline Genista & Ano 10 & n. 21 & Janeiro - Abril 2021 & p. $189-207$ \\
\hline
\end{tabular}


SCHÜTZ, Rosalvo. Transcender sem transcendência: elementos para uma reabilitação materialista da religião. In: Revista Veritas. Porto Alegre,65(1), e36155, 2020. https://doi.org/10.15448/1984-6746.2020.1.36155.

SOUZA, Draiton Gonzaga de. O ateísmo antropológico de Ludwig Feuerbach. 2. ed. Porto Alegre: EDIPUCRS, 1994.

VIDAL, Francesca. Sherlock Holmes nos estudos culturais. Tradução de Rosalvo Schütz e Adriano Steffler. Revista Dialectus, ano 01, n. 2, janeiro-junho 2013, p. 279-295. 